\title{
Tef Yield Response to NPS Fertilizer and Methods of Sowing in East Shewa,
} Ethiopia

\section{Wakjira Tesfahun ${ }^{1}$}

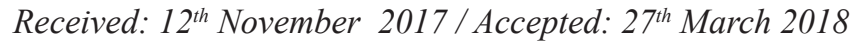

\begin{abstract}
Purpose: Soil fertility maintenance is a major concern in tropical Africa which needs to tackle soil fertility depletion as fundamental constraints. Similarly, the traditional way of planting tef reduces the amount of grain production, promotes competition for inputs and causes severe lodging. In this view, a study was to investigate the effect of sowing methods and NPS fertilizer application on tef production.

Research method: A factorial experiment was laid out in RCBD with12 treatment combination and three replications at DebreZeit Agricultural Research Center. The first factor included six NPS fertilizer rates and the second factor included two methods of sowing. Relevant data were gathered and analyzed using SAS and mean difference were compared using LSD.

Findings: The results of the study revealed that the analysis of variance among fertilizer rates and method of sowing showed significant differences $(P \leq 0.05)$ on almost all the tef characters tested. The shortest mean days to $50 \%$ panicle emergence (57.5) of teff were obtained from $120 \mathrm{~kg}$ of NPS fertilizer. However, applied NPS fertilizer showed no significant difference on tef physiological maturity. The highest grain yield $\left(3.77 \mathrm{t} \mathrm{ha^{-1 }}\right)$, biomass yield $\left(10.09 \mathrm{t} \mathrm{ha}^{-1}\right)$ and straw yield $\left(6.32 \mathrm{t} \mathrm{h \textrm {a } ^ { - 1 }}\right)$ were recorded from combination of $120 \mathrm{~kg}$ NPS fertilizer and transplanting method. Blended fertilizer together with transplanting had improved the number of effective tiller and grain yield, biomass yield as well as straw yield. Therefore, $120 \mathrm{~kg} \mathrm{ha}$-1 of NPS fertilizer and transplanting method can be suggested as one effective way to maximize grain yield of tef.
\end{abstract}

Research Limitation: Further validation and demonstrations across multiple areas would be necessary to make conclusive recommendation since the experiment was conducted for sole season and site.

Originality/Value: This study provides insights for farmers and stakeholders to incorporate blended fertilizer for soil fertility amendment and in encouraging of tef transplanting technology for boosting production.

Keywords: NPS fertilizer, teff yield, method of sowing

\section{INTRODUCTION}

In Ethiopia, tef is cultivated on an area of about 3 million hectares with tef and maize taking up about $24.02 \%$ and $16.8 \%$ of the total grain crop area, respectively. This makes tef the first among cereals in the country in area coverage (CSA, 2015). Despite large coverage, its productivity is very low. The average national yield of tef is about 1.64 tons per ha (CSA, 2015). Some of the factors contributing to the low yield of tef are low soil fertility and suboptimal use of fertilizers, weeds, and erratic rainfall distribution and drought particularly in the areas of low altitude, lack of high yielding cultivars, lodging and water-logging (Ermias et al., 2007).

Soil fertility maintenance is a major concern in tropical Africa, predominantly with the rapid population increase, which has occurred in the past few decades. Improving food production

${ }^{1}$ Raya University, College of Agriculture and Natural Resource, Ethiopia.Wakjiratesfahun@gmail.com 
and soil resources in the smallholder farm sector of Africa has become an enormous challenge (Dagne,2016). According to the soil fertility map made over 150 districts, Ethiopian soil lacks about seven nutrients (N, P, K, S, Cu, Zn and B) (EthioSIS, 2013). Based on the EthioSIS (Ethiopian soil information system) soil analysis report of 2013 the study area lack Sulphur in addition to the low level of Phosphorus.

The most common way of planting tef is by broadcasting the small seed at the rate of $25-50$ $\mathrm{kg} \mathrm{ha}^{-1}$ (Bekalu and Tenaw, 2015). This practice reduces the amount of grain production, promotes competition among plants for inputs and causes severe lodging; which is the main cause for low yield of tef due to high plant density (Fufa et al., 2011).Using the technology of row planting or transplanting, weeding can be done much more readily and the lodging incidence is reduced (Chanyalew and Kebede, 2013).Thus, it is important to develop an appropriate sowing method and balanced mineral NPS fertilizer application recommendations in the study area for enhancing productivity of the crop and food security. However, limited research has been done to elucidate the response of tef variety to mineral NPS fertilizer application and method of sowing in the study area. This study was therefore, initiated with the following objectives.

- To evaluate the effect of different sowing methods and NPS fertilizer application on growth, yield and yield components of Tef;

- To investigate the interaction effects sowing methods and NPS fertilizer application on growth, yield and yield components of Tef

\section{MATERIALS AND METHODS}

\section{Description of the Study Area}

The study was conducted at Debre Zeit Agricultural Research Center in Oromia National Regional State during the main cropping rainy season of 2017. The site is located of $8^{0}-44^{\prime} \mathrm{N} \& 38^{\circ}-58^{\prime} \mathrm{E}$ at an altitude of 1900 m.a.s.1. The area is characterized by monomodal rainfall pattern. The mean longterm annual rainfall recorded at the station is $660 \mathrm{~mm}$ and the average annual minimum and maximum temperatures are $12^{\circ} \mathrm{C}$ and $27.4^{\circ} \mathrm{C}$, respectively. The experimental soil was silt loam texture composed of $14 \%$ clay, $32 \%$ sand and 54\% silt: having an organic carbon content of $1.26 \%$ which is low according to Roy et al., (2006). The soil had medium OC in accordance with Sahlemedhin and Taye (2000). The CEC of the soil was $33.33 \mathrm{meq} \mathrm{kg}^{-1}$, which is considered as high. According to Hazelton and Murphy (2007) CEC rating, 25- 40 is high. According to Olsen et al., (1954) $\mathrm{P}$ rating $\left(\mathrm{mgkg}^{-1}\right), \mathrm{P}$ content of $<3$ is very low, 4 to 7 is low, 8 to 11 is medium, and $>11$ is high. Thus the experimental site of available $\mathrm{P}$ content is low. The $\mathrm{pH}$ of the soil was 6.96 , which is within the range of 4 to 8 suitable for tef production (2000) Total $\mathrm{N}$ of the soil $(0.12 \%)$, is medium; as rated by Havlin et al., (1999) who rated total $\mathrm{N}$ between 0.15 to $0.25 \%$ as medium.

\section{Materials Used for the Experiment}

The tef variety named Quncho (DZ-Cr-387-RIL 355 was used for the experiment. Quncho is a high yielding, white-seeded cultivar adapted to a wide range of altitudes (MoARD, 2008). Urea and NPS $(19 \% \mathrm{~N}, 38 \% \mathrm{P}$ and $7 \% \mathrm{~S})$ fertilizers were used as a source of nitrogen, phosphorus and Sulphur nutrient respectively.

\section{Treatment and Experimental design}

The treatments were consisted of six rates of NPS (0 30, 60, 90,120 and $150 \mathrm{~kg}$ of NPS ha-1) and two methods of sowing (transplanting and row planting). The treatments were laid out as a Random complete block design in a factorial arrangement and replicated three times. A plot size of $1.6 \mathrm{~m} \mathrm{x} 2 \mathrm{~m}\left(3.2 \mathrm{~m}^{2}\right)$ with $20 \mathrm{~cm}$ row spacing and a total of 8 rows were used. The net harvestable area was $1.2 \mathrm{~m} \times 1.6 \mathrm{~m}$ and adjacent plots and blocks were spaced 0.5 and $1 \mathrm{~m}$ apart, respectively. Treatments were assigned to each plot randomly. 


\section{Experimental procedure}

Land was prepared according to the local practice. It was ploughed five times using oxen before planting and the last plough was used for sowing. After the seedbeds leveled and compacted, seeds were (transplanting and row method) as per treatment. NP-S fertilizer was applied during planting on the basis of the treatment, and after thinning nitrogen was applied (side dressing) at a rate at the rate of $90 \mathrm{~kg} \mathrm{ha}^{-1}$; in which $1 / 3$ at planting and $2 / 3$ at stem elongation in the form of Urea. The seed rates of Tef were used $5 \mathrm{~kg} \mathrm{ha}^{-1}$ and $0.5 \mathrm{~kg}^{-} \mathrm{ha}^{-}$ ${ }^{1}$ for row sowing and transplanting respectively. The required cultural practices were applied as per the recommendations of Seyfu (2007).

\section{Soil Sampling and chemical Analysis}

One representative composite sample was taken at a depth of 0-30 cm from five randomly selected spots diagonally across the experimental field using auger before planting and bulked. Working sample was obtained from the submitted sample and analyzed for selected physico-chemical properties mainly texture, bulk density, soil $\mathrm{pH}$, cation exchangeable capacity (CEC), organic carbon, total $\mathrm{N}$, and available $\mathrm{P}$ using standard laboratory procedures at Debre Zeit Agricultural Research Center soil laboratory.

\section{Data Collection and Measurements}

Days to panicle emergence and physiological maturity of tef were recorded when $50 \%$ and $90 \%$ of the plants in a plot reached to their respective phenological stage. Plant height was measured at physiological maturity from the ground level to the tip of panicle from ten randomly selected plants in each plot. Panicle length was measured from the node where the first panicle branch emerges to the tip of the panicle and it was determine from an average of ten selected plants per plot. The numbers of total and effective tillers were determined by counting the tillers from an area of $0.25 \mathrm{~m} \mathrm{x}$
$0.25 \mathrm{~m}$ plants by throwing a quadrat into the middle portion of each plot. Biomass yield was measured by weighing the sun- dried total above ground plant biomass of the net plot at physiological maturity. The grain yield was measured by taking the weight of the grains from the net plot area and converted to tone per hectare after adjusting the grain moisture content to $12.5 \%$. Straw yield was determined by subtracting grain yield from total above ground biomass. Harvest index was calculated on a plot basis as the ratio of grain yield to the aboveground biomass yield and expressed as a percentage. Lodging was assessed just before the time of harvest by visual observation based on the scales of $1-5$ where $1\left(0-15^{\circ}\right)$ indicates no lodging and $5\left(60-90^{\circ}\right)$ indicates $100 \%$ lodging (Donald, 2004).

\section{Statistical Data Analysis}

Data were subjected to analysis of variance (ANOVA) using General Linear Model (GLM) procedures of SAS 9.1.3 (SAS, 2002). Differences among treatment means were compared using Least Significant Difference test at $5 \%$ level of significance.

\section{RESULTS AND DISCUSSION}

\section{Phenological parameter}

The analysis of variance indicated that there was a significant difference in days to panicle emergence with respective fertilizer rate and no significant difference to days to physiological maturity (data not shown). NPS fertilizer hastened the number of days required to heading compared to control. Generally as the rate of NPS increased, the number of days elapsed to heading was shortened. Hence, the longest days (70 days) to heading was recorded from control plots while the shortest days (59 days) to heading was recorded from 90 and 120 $\mathrm{kg} \mathrm{ha}^{-1}$ of NPS fertilizer (Figure 01). 


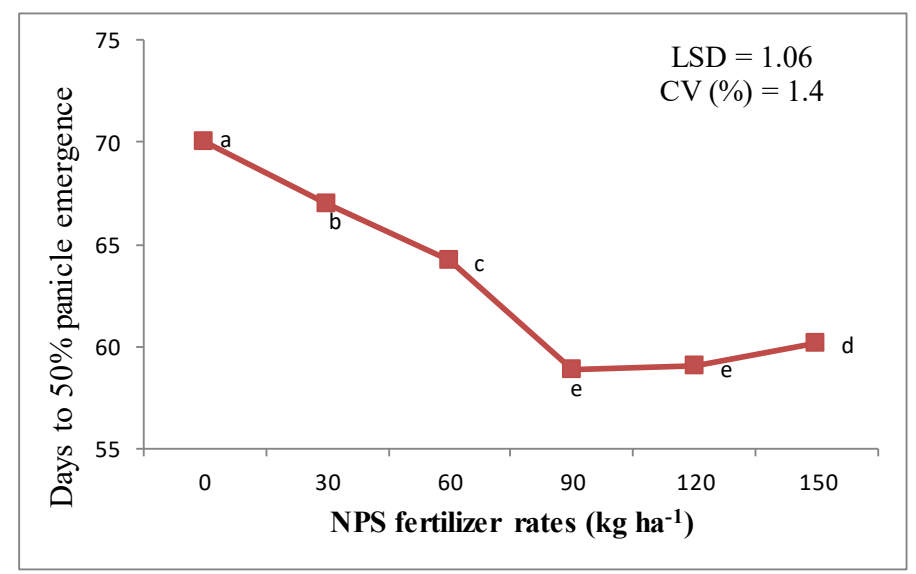

Figure 01: Main Effect of NP-S fertilizer application on Days to $50 \%$ panicle emergence of tef

Blended fertilizer hastened the numbers days elapsed to heading. This might be plots that received nutrients which have possibility to early establishment, fast growth and development which is similarly reported by Tucker (1999). The delayed heading at lower rate of the nutrients could be the result due to longer time required to establish, grow and complete the vegetative growth. Similarly Tolosa (2012) reported that application of NP application significantly shortened days to heading of tef than control.

\section{Vegetative growth parameters}

\section{Plant height and panicle length}

The analysis of variance showed that plant height and panicle length were significantly influenced by interaction effects of NP-S fertilizer and method of sowing (Table 01). The highest plant height recorded from transplanted plant applied at a rate of $120 \mathrm{~kg}(119.97 \mathrm{~cm})$ and from row planted that applied at a rate of $90 \mathrm{~kg}(117.33 \mathrm{~cm})$ NP-S fertilizer while the lowest plant height $(82.03 \mathrm{~cm})$ observed from row planted at nil rate NPS fertilizer NP-S application (Table 01). The highest panicle length $(54.63 \mathrm{~cm})$ was recorded from transplanted that applied at a rate of $120 \mathrm{~kg} \mathrm{ha}^{-1}$ NPS fertilizer, followed $(46.63 \mathrm{~cm})$ by transplanted with $90 \mathrm{~kg} \mathrm{NPS} \mathrm{ha}^{-1}$, while the lowest panicle length $(31.33 \mathrm{~cm})$ was record from row planted that supplied with nil NPS application (Table 01).

Table 01: The Interaction effect of method of planting and NP-S fertilizer rate on plant height and panicle length of tef.

\begin{tabular}{ccccc}
\hline & \multicolumn{4}{c}{ Method of planting } \\
\cline { 2 - 4 } NPS fertilizer rate $\left(\mathrm{Kg} \mathrm{ha}^{-1}\right)$ & \multicolumn{2}{c}{ Plant height $(\mathrm{cm})$} & Panicle length $(\mathrm{cm})$ \\
\cline { 2 - 4 } & Row method & Transplanting & Row method & Transplanting \\
\cline { 2 - 4 } 0 & $82.03^{\mathrm{h}}$ & $89.50^{\mathrm{g}}$ & $31.33^{\mathrm{i}}$ & $33.63^{\mathrm{h}}$ \\
30 & $92.68^{\mathrm{f}}$ & $94.50^{\mathrm{f}}$ & $35.80^{\mathrm{g}}$ & $38.23^{\mathrm{f}}$ \\
60 & $100.00^{\mathrm{d}}$ & $98.87^{\mathrm{de}}$ & $37.90^{\mathrm{f}}$ & $42.10^{\mathrm{d}}$ \\
90 & $117.33^{\mathrm{a}}$ & $111.10^{\mathrm{b}}$ & $44.60^{\mathrm{c}}$ & $46.43^{\mathrm{b}}$ \\
120 & $103.90^{\mathrm{c}}$ & $119.97^{\mathrm{a}}$ & $39.87^{\mathrm{e}}$ & $54.63^{\mathrm{a}}$ \\
150 & $97.40^{\mathrm{e}}$ & $104.20^{\mathrm{c}}$ & $36.63^{\mathrm{h}}$ & $40.47^{\mathrm{e}}$ \\
LSD & 1.96 & & 1.56 & \\
CV $(\%)$ & 3.18 & & 2.35 & \\
\hline
\end{tabular}

Means with the same letter(s) in the same columns and row of each parameter are not significantly different at 5\% probability level, $C V(\%)=$ coefficient of variation 
The increase in plant height with increasing NPS fertilizer could be attributed due to sufficient supply of nutrient which in turn facilitates plants growth since nitrogen plays a crucial role in the structure of chlorophyll and P involved in the energy transfer for cellular metabolism. This result was in agreement with the findings of (Alemu et al., 2016; Giday et al., 2014). Similarly, application of blended fertilizers was on par with blanket recommendation of fertilizers and gave significantly higher plant height on wheat. Similar to plant height panicle length increased with similar reason. According to Feyera et al., (2014) balanced fertilization application and efficient utilization of nutrient leads to high photosynthetic productivity and accretion of dry matter, eventually increases panicle length. Akhagri and Kaviani (2011) who reported that transplanting method of sowing increased panicle length than row method of planting. Plant height also increased in transplanting method similar to panicle length; this also is in agreement with the results reported by Abadi (2009) on rice. This increment in plant height and panicle length due to transplanting might be attributed less competition for growth resource due to the available space which in turn creates good growing environment for a plant to grow actively.

\section{Yield related parameter}

\section{Effects on fertile and total tiller}

The analysis of variance indicated that fertile and total tiller were significantly affected by main effects of method of sowing and NP-S blended fertilizer (Table 02). The highest fertile tiller (15.47) was obtained from main effect of transplanted plants and lowest fertile tiller (10) was recorded from row planted. Total and Fertile tiller increased consistently and significantly in response to increasing the rate of NPS fertilizer from nil up to $120 \mathrm{~kg}$ NPS $\mathrm{ha}^{-1}$. However, increasing the rate of the NPS fertilizer from 120 to $150 \mathrm{~kg} \mathrm{~N}^{-1}$ did not increase the number of total and fertile tiller. The highest fertile tiller was obtained at a rate of NPS fertilizer $90 \mathrm{~kg}$ (15.55) and 120 (15.17) $\mathrm{kg} \mathrm{ha}^{-1}$ were in statistical parity and the lowest number of fertile tiller (11.5) was recorded at nil application rate of the fertilizer.

Table 02: Main effect of method planting and NP-S fertilizer rate application on fertile and total tillers of tef

\begin{tabular}{ccc}
\hline Treatments & & \\
\hline Methods of sowing & Fertile tiller & Total tiller \\
\hline Row & $10.12^{\mathrm{b}}$ & $12.44^{\mathrm{b}}$ \\
trans & $15.47^{\mathrm{a}}$ & $18.18^{\mathrm{a}}$ \\
LSD & 0.48 & 0.52 \\
\hline Fertilizer Rate $\left(\mathrm{kg} \mathrm{NPS} \mathrm{ha}^{-1}\right)$ & & \\
\hline 0 & $8.62^{\mathrm{e}}$ & $11.50^{\mathrm{d}}$ \\
30 & $11.42^{\mathrm{d}}$ & $13.62^{\mathrm{c}}$ \\
60 & $13.72^{\mathrm{b}}$ & $15.75^{\mathrm{b}}$ \\
90 & $15.55^{\mathrm{a}}$ & $17.32^{\mathrm{a}}$ \\
120 & $15.17^{\mathrm{a}}$ & $18.17^{\mathrm{a}}$ \\
150 & $12.28^{\mathrm{c}}$ & $15.47^{\mathrm{b}}$ \\
\hline LSD & 0.83 & 0.91 \\
CV $(\%)$ & 5.30 & 5.10 \\
\hline
\end{tabular}

Means with the same letter(s) in the same columns and row of each parameter are not significantly different at $5 \%$ probability level, $\mathrm{CV}(\%)=$ coefficient of variation 
The highest total tiller was recorded from plants that supplied with 90 and $120 \mathrm{~kg}$ of NPS which gave 18.17 and 17.32 respectively and the lowest number of total tiller (11.5) was obtained at nil application rate of fertilizer (11.5). Main effect of method of sowing affects total tillers, in which transplanted (18.18) gain advantage over row planting (12.44) by producing more total tiller and improved total tiller production by $31.57 \%$ ( Table 04 ).

Total tiller increased across the increasing rate of the NPS fertilizer. The possible reason for increment in number of tiller might be due to the effect of balanced fertilization in which readily soluble minerals help to the vegetative growth of the crop. The current result is in line with the findings of Fayera et al., (2014) who found that blended fertilizer produced a high number of tillers and effective tillers. Similar results have also been found where blended fertilizer produces a high number of tillers and effective tillers. In contrast with the results of this study, the number of productive tiller of tef was not influenced by blended fertilizer (Fayera et al., 2014) Ehsanuah et al., (2007) and Awan et al., (2011) on rice and Tareke and Nigusse (2008) on tef reported that transplanting had more tiller number, and fertile tiller than direct sowing.

\section{Effects on Biomass and straw yield}

The analysis of variance indicated that biomass and straw yield were significantly affected by interaction effects of the method of sowing and NP-S fertilizer (Table 03). The highest biomass yield (10.09 t/ha) was obtained from combination of transplanted plant and $120 \mathrm{~kg}$ NP-S fertilizer and the lowest biomass yield (8.033 t/ha) was obtained from combination of nil NP-S application and row planted (Table 03).

The combination of transplanted and $120 \mathrm{~kg}$ NPS fertilizer gave the highest straw yield $\left(6.32 \mathrm{t} \mathrm{ha}^{-1}\right)$ while the lowest straw yield (5.53 $\left.\mathrm{t} \mathrm{ha}^{-1}\right)$ was recorded from the interaction of row planted and nil NP-S fertilizer. Application of NPS fertilizer up to $90 \mathrm{~kg} \mathrm{ha}^{-1}$ was found to increase straw yield by $55.7 \%$ while application further from this point was found to decreased straw yield by $6.4 \%$ in row method. Similarly, application of NPS fertilizer on transplanted plant up to $120 \mathrm{~kg} \mathrm{ha}^{-1}$ increased straw yield $61 \%$ but, further increasing of the same up to $150 \mathrm{~kg}$ decreased straw yield by $16 \%$ (Table 3 ).

The significant increase in biomass and straw yield could be attributed due to the availability of macronutrients and some secondary nutrients formulated with the blended fertilizer, which could increase the vegetative consequently to the biomass of yield. Similar significant increase in biomass yield was also observed for different application of blended fertilizers (Fayera et al., 2014) which states that the increase in biomass yield attributed due to the proportional vegetative growth especially the plant height.

Table 03: Interaction effect of method of sowing and NP-S fertilizer rate on Biomass and straw yield of tef

\begin{tabular}{|c|c|c|c|c|}
\hline \multirow{3}{*}{$\begin{array}{l}\text { Treatments } \\
\text { NPS fertilizer rate }\left(\mathrm{Kg} \mathrm{ha}^{-1}\right)\end{array}$} & \multicolumn{4}{|c|}{ Methods of sowing } \\
\hline & \multicolumn{2}{|c|}{ Biomass yield (ton ha-1) } & \multicolumn{2}{|c|}{ Straw yield (ton ha-1) } \\
\hline & Row method & Transplanting & Row method & Transplanting \\
\hline 0 & $8.03^{\mathrm{i}}$ & $8.41^{\mathrm{hi}}$ & $5.53^{\mathrm{g}}$ & $5.71^{\mathrm{ef}}$ \\
\hline 30 & $8.51^{\mathrm{gh}}$ & $8.74^{\mathrm{e}}$ & $5.71^{\mathrm{ef}}$ & $5.77^{\text {ed }}$ \\
\hline 60 & $8.69^{\mathrm{ef}}$ & $9.04^{\mathrm{d}}$ & $5.67^{\mathrm{f}}$ & $5.83^{\mathrm{d}}$ \\
\hline 90 & $9.54^{\mathrm{b}}$ & $9.60^{\mathrm{b}}$ & $6.08^{c}$ & $6.22^{b}$ \\
\hline 120 & $8.59^{\mathrm{fg}}$ & $10.09^{\mathrm{a}}$ & $6.08^{c}$ & $6.32^{\mathrm{a}}$ \\
\hline 150 & $8.36^{\mathrm{h}}$ & $9.36^{\mathrm{c}}$ & $5.69^{\mathrm{ef}}$ & $6.16^{\mathrm{bc}}$ \\
\hline LSD & 1.4 & & 0.78 & \\
\hline $\mathrm{CV}(\%)$ & 0.88 & & 0.81 & \\
\hline
\end{tabular}

Means with the same letter(s) in the same columns and row of each parameter are not significantly different at 5\% probability level, CV $(\%)=$ coefficient of variation 
On the other hand, the increment in straw and biomass yield from the variation between methods of sowing could be attributed due to wider space and supplied with balanced fertilizer, fully availed soil moisture and solar radiation for the production of more tillers, taller and heavy plants. Also Alemu et al., (2016) on its report stated that the increase biomass yield is due secondary branch and leaf number and size which were grown during grain filling period beside panicle length and plant height. These results are also strengthened by the report of Tareke (2010) who got higher number of productive tillers and heavy panicle bearing culms, which contributed to increase biomass and straw yield. Other studies on rice indicate that transplanting method of planting increased biomass and straw yields compared to row method (Maqsood, 1998).

\section{Effects on Grain yield}

The analysis of variance showed that plant height was significantly influenced by interaction effects of NP-S fertilizer and method of sowing (Table 04). Grain yield increased consistently and significantly in response to increasing the rate of NPS fertilizer from nil up to $120 \mathrm{~kg}$ NPS ha $^{-1}$ with transplanting. However, increasing the rate of the NPS fertilizer from 120 to 150 $\mathrm{kg}$ NPS ha ${ }^{-1}$ did not increase grain yield. The highest grain yield(3.77) was obtained at a rate of NPS fertilizer $120 \mathrm{~kg} \mathrm{ha}^{-1}$ and transplanting.
However, the lowest grain yield was produced at nil application rate of the fertilizer with row planted (Table 04).

The significant increase in grain yield in response to using transplanting might be attributed due to less competition for growth resource like water, sunlight and nutrients, better air circulation which reduces the occurrence of insect pest and disease infestation and also uniform plant stands given opportunity to suppress weed growth. The maximum grain yield obtained using transplanting could be attributed to sufficient amount of moisture and nutrients available to the plants due to deep penetration and wide spread of roots at the time of flowering stage which eventually prevents abortion of seed and in more panicle bearing and florets per panicle. The increase in grain yield from blended fertilizer might be facilitated the uptake of other essential nutrients which helps to boost plant growth and yield This finding is also similar to Tareke et al., (2013) who reported that transplanting increased grain yield by increasing productive tillers and reducing lodging. Similar results also reported blended fertilizer increased grain yield of tef Tareke et al.,(2013) on his work reported that transplanting combined with blended fertilizer increased grain yield by $50 \%$ than using DAP or Urea fertilizer, and this increment in grain yield is mainly due to the number of tillers and number of panicle.

Table 04: Interaction effect of method of planting and NP-S fertilizer rate on Grain yield and Harvest index of tef

\begin{tabular}{ccccc}
\hline \multicolumn{5}{c}{ Methods of sowing } \\
\hline NPS fertilizer rate $\left(\mathrm{Kg} \mathrm{ha}^{-1}\right)$ & \multicolumn{2}{c}{ Grain yield (ton ha $\left.{ }^{-1}\right)$} & \multicolumn{2}{c}{ Harvest index $(\%)$} \\
\hline 0 & Row method & Transplanting & Row method & Transplanting \\
\hline 30 & $2.5^{\mathrm{g}}$ & $2.703^{\mathrm{f}}$ & $31.13^{\mathrm{j}}$ & $32.12^{\mathrm{i}}$ \\
60 & $2.8^{\mathrm{e}}$ & $2.973^{\mathrm{d}}$ & $32.91^{\mathrm{h}}$ & $33.99^{\mathrm{fg}}$ \\
90 & $3.020^{\mathrm{d}}$ & $3.213^{\mathrm{c}}$ & $34.76^{\mathrm{ed}}$ & $35.53^{\mathrm{c}}$ \\
120 & $3.457^{\mathrm{b}}$ & $3.38^{\mathrm{b}}$ & $36.22^{\mathrm{b}}$ & $35.20^{\mathrm{cd}}$ \\
150 & $2.877^{\mathrm{e}}$ & $3.77^{\mathrm{a}}$ & $33.48^{\mathrm{g}}$ & $37.53^{\mathrm{a}}$ \\
LSD & $2.673^{\mathrm{f}}$ & $3.203^{\mathrm{c}}$ & $34.22^{\mathrm{ef}}$ & $34.22^{\text {ef }}$ \\
CV (\%) & 0.85 & & 0.55 & \\
\hline
\end{tabular}

Means with the same letter(s) in the same columns and row of each parameter are not significantly different at $5 \%$ probability level, $C V(\%)=$ coefficient of variation in percent 


\section{Effect on harvesting index}

Analysis of variance showed that lodging index was significantly influenced by interaction effects of NP-S fertilizer and methods of planting (Table 04). The highest HI (37.53\%) was obtained from transplanted plant at a rate of $120 \mathrm{~kg}$ NP-S fertilizer application, followed by row planted (36.22\%) and 90kg NP-S fertilizer, while the least HI $(31.13 \%)$ was obtained from nil fertilizer application in both methods of sowing (Table 04).

The significant difference in harvesting index obtained from blended fertilizer might be attributed of sufficient quantity of nutrients particularly $\mathrm{P}$ for translocation to sink. In line with this result Gebrekidan and Seyoum (2006) reported that harvesting index increases with the application of $\mathrm{P}$ fertilizer rate. Transplanting takes an advantage in increasing harvesting index, which might help the plant to utilize growth resources (including solar radiation) in a better way to produce high grain yield.

\section{Effect on lodging index}

The analysis of variance showed that lodging index was significantly influenced by and interaction effects of NP-S fertilizer and the method of planting (Figure 02). The highest lodging index (62.4\%) was recorded from transplanted plant that supplied with $150 \mathrm{~kg}$ NPS $\mathrm{ha}^{-1}$ and the lowest lodging index was obtained from row planted with nil fertilizer application.

The increasing lodging index with increasing NPS fertilizer could be attributed from an increase of plant height since plant height and lodging index are positively correlated due to this reason and the plants tend to lodge. Similar reports were recorded in increasing lodging percentage of tef (Tolosa, 2012) which articulated that lodging increased from addition of more NPK application. Also Kebebew (1991) and Tams et al., (2004) confirmed that abundant supply of nutrients in the soil can contribute to the process of lodging. The significant difference in lodging between methods of sowing might be attributed from heavy panicle that bears by culm of the plant due to favorable environmental conditions particularly for the transplanting method. These results are strengthened by Takele (2010) who observed that transplanted plant was lodged due heavy panicles and high plant height.

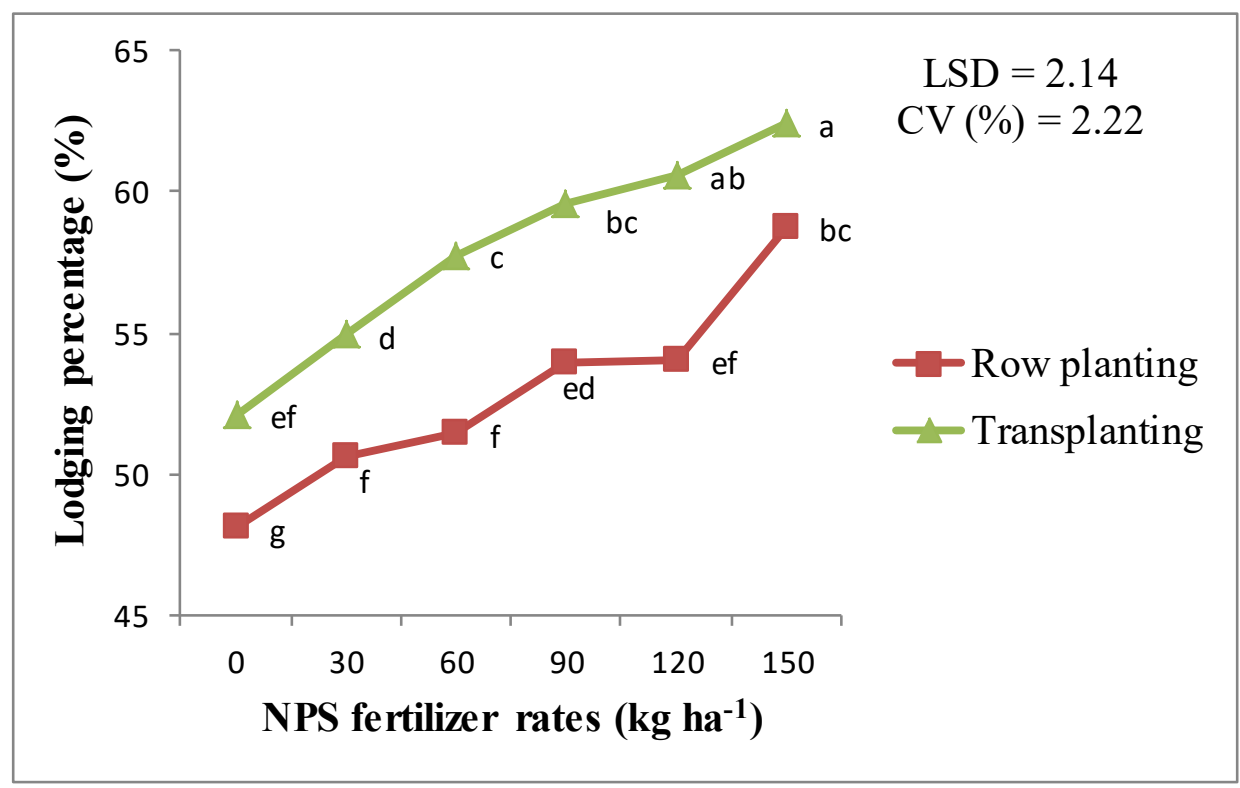

Figure 02: Interaction effect of method of planting and NP-S fertilizer rate on lodging index of tef 


\section{CONCLUSION}

Appropriate fertilization practices based on actual limiting of nutrients and crop requirement for a given crop is economic and judicious use of fertilizers for sustainable crop production. According to this study NPS fertilizer effects on tef yield and yield components showed that the blended fertilizers would be promising to grow tef in the study area compared to DAP and Urea combination. Thus indicated that tef productivity in the study sites was increased due to transplanting and NPS fertilizer, in which the results of the study revealed that the maximum mean grain yield $(8399.7 \mathrm{~kg}$ ha-1), straw yield (8553.1 kg ha-1) and total biomass yield (16867.7 kg ha-1) were recorded for $120 \mathrm{Kg}$ NPS fertilizers in the transplanting method of sowing. To improve the current unbalanced fertilizer application and soil mining of the study sites, preventative actions such as adopting sustainable soil fertility replenishment strategy, soil conservation practices and avoiding unbalanced fertilizers can help to rebuild the soil conditions to increase crop productivity. From this point of view, the combination of transplanting with 120 $\mathrm{kg}$ NPS ha-1 application was the best treatment combination for producing high grain and straw yield. Therefore, this treatment can be suggested for farmers in the study area. However, an exact recommendation may not be drawn from this research result since it was conducted only for the sole season. Therefore, the experiment has to be conducted in multi-location for sound recommendation.

\section{REFERENCES}

Abadi Berehe.(2009). Effect of planting methods on yield and yield components of rice (Oryaza sativa L.) varieties in Tahtay Koraro Wereda, Northern, Ethiopia. International Journal of Technology Enhancements and Emerging Engineering Research, vol. 1(5) ISSN 2347-4289. DOI: http://dx.doi.org/10.3923/ijar.2014.259.264

Akhgari, H., and Kaviani, B. (2011). Assessment of Direct Seeded and Transplanting methods of Rice Cultivars in the Northern part of Iran. African Journal of Agricultural Research.6 (31), pp. 6492-6498. DOI: http://dx.doi.org/10.5897/ajar11.973

Alemu Assefa, Tamado Tana, Jemal Abdulahi. (2016) Effects of Compost and Inorganic NP Rates on Growth, Yield and Yield Components of Teff (Eragrotis teff (Zucc.) Trotter) in Girar Jarso District, Central Highland of Ethiopia. Journal of Fertilizer and Pesticide 7: 174. DOI: http://dx.doi.org/10.4172/2471-2728.1000174

Awan, T. H., Ahmad, M., Ashraf, M. M., and Ali, I. (2011)."Effect of Different Transplanting Methods on Paddy Yield and Its Components at Farmers' field in Rice zone of Punjab. The Journal of Animal and Plant Sciences, vol.21, no.3, pp. 498-502. DOI: http://dx.doi. org/10.3923/ajps.2002.117.118

Bekalu Abebe and Tenaw Workayehu .(2015). Effect of Method of Sowing and Time of DiAmmonium Phosphate (DAP) Fertilizer Application, on Yield and Yield Components of Tef ((Eragrostic tef) Trotter) At Shebedino, Southern Ethiopia. Advanced Crop Science. Technology 3: 168. .DOI: http://dx.doi.org/10.4172/2329-8863.1000168

CSA (Central Statistic Authority). (2015) Agricultural Sample Survey: report on Area and production of major Crops (Private peasant holdings "meher"season), Volume I Addis Abeba, Ethiopia. DOI: http://dx.doi.org/10.15415/jmrh.2015.21005 
Chanyalew Sebsebe. and Kebede Assefa. (2013). The agronomy of tef. Paper presented at the "Improved evidence towards better policies for the teff value chain" conference, 10 October 2013, Addis Ababa, Ethiopia. DOI: http://dx.doi.org/10.2147/idr.s134369

Dagne Chimdessa. (2016). Blended Fertilizers Effects on Maize Yield and Yield Components of Western Oromia, Ethiopia. Agriculture, Forestry and Fisheries 5(5), pp. 151-162. DOI: http://dx.doi.org/10.11648/j.aff.20160505.13

Donald, L.S. (2004). Understanding and reducing lodging in cereals. Advances in Agronomy 84: 217-271. DOI: http://dx.doi.org/10.1016/s0065-2113(04)84005-7

Ehsanullah, Akbar, N., Jabran, K., and Habib, T .(2007). Comparison of Different planting Methods for Optimization of Plant Population of Fine Rice (Oryza sativa L.) in Punjab, Pakistan. Pakistan Journal of Agricultural Science .44(4) pp. 597-599. DOI: http://dx.doi. org/10.3923/pjbs.2001.1188.1190

Ermias Abate, Akalu Teshome, Alemayehu Assefa, Melaku Wale, and Tilahun Tadesse. (eds) (2007). Proceedings of the 1st Annual Regional Conference on Completed Crop Research Activities, 14-17 August 2006. Amhara Regional Agricultural Research Institute - Bahir Dar, Ethiopia. DOI: http://dx.doi.org/10.1186/s13104-017-2573-1

EthioSIS (Ethiopian soil information system). (2013). Soil analysis report agricultural agency. DOI: http://dx.doi.org/10.1080/00103624.2016.1166378

Feyera Asefa, Adugna Debela and Muktar Mohammed .(2014). Evaluation of teff [Eragrostis tef (Zuccagni) Trotter] responses to different rates of NPK along with Zn and B in Didessa district, southwestern Ehiopia. World Applied Sciences Journal 32: 2245-2249. DOI: http:// dx.doi.org/10.19080/artoaj.2016.02.555593

Food and Agricultural Organization (FAO) (2000) Fertilizers and Their Use $4^{\text {thed. }}$. International fertilizer industry association, FAO, Rome, Italy, pp. 34. DOI: http://dx.doi. org/10.2172/1329289

Fufa Hundera B.,B.Behute, R.Simons, and T.Berhe. (2011).“Tef Diagnostic Report: Strengthening the Tef Value Chain in Ethiopia”. Addis Ababa, Ethiopia. DOI: http://dx.doi.org/10.1111/ j.1601-5223.2001.00103.x

Gebrekidan Heluf and Seyoum Mulgeta .(2006). Effects of mineral N and P fertilizers on yield and yield components of flooded lowland rice on vertisols of Fogera plain, Ethiopia. Journal of Agriculture and Rural Development in the Tropics and Subtropics 107: pp. 161176. DOI: http://dx.doi.org/10.11648/j.aff.20160505.13

Giday O, Gibrekidan H, Berhe T. (2014). Response of teff (Eragrostis tef) to different rates of slow release and conventional urea fertilizers in vertisols of southern tigray, ethiopia. Advances in Plants and Agriculture Research. DOI: http://dx.doi.org/10.15406/apar.2014.01.00030

Havlin, J.L., Beaton, J.D., Tisdale, S.L and Nelson, W.L.(1999). Functions and forms of N in plants. In Soil Fertility and Fertilizers. (6 ${ }^{\text {th }}$ ed) Prentice Hall, New Jersey. DOI: http://dx.doi. org/10.1097/00010694-195704000-00019 
Hazelton, P. and Murphy, B. (2007). Interpreting soil test results: What do all the numbers mean? Second Edition. CSIRO Publishing. Pp. 152. DOI: http://dx.doi.org/10.1111/j.13652389.2007.00943_8.x

Kebebew Assefa. (1991). Effects of some synthetic plant growth regulators on lodging and other agronomic andmorphological characters of tef [Eragrostis tef, (Zucc.) Trotter]. M.Sc. Thesis, Alemaya University of Agriculture, Alemaya, Ethiopia. DOI: http://dx.doi.org/10.1111/ j.1439-0523.2010.01782.x

Maqsood, M. (1998). Growth and yield of rice andwheat as influenced by different planting methods and nitrogen levels in rice-wheat cropping' system. Ph.D. Thesis, Univ. Agri.,Faisalabad. DOI: http://dx.doi.org/10.3329/brj.v19i2.28164

Ministry of Agriculture and Rural Development (MoARD). (2008). Crop Variety Register, Animal and Plant Health Regulatory Directorate, Addis Ababa, Ethiopia, June 2008. DOI: http:// dx.doi.org/10.12980/jclm.4.2016j6-95

Olsen, S. R.,Cole C. W.,Watanabe,F.S. and Dean, L.A.(1954). Estimation of available phosphorous in soils by extraction with sodium bicarbonate Circular 939,US. Department of agriculture. DOI: http://dx.doi.org/10.1097/00010694-196005000-00010

Roy, R.N., Finck, A., Blair ,G.J. and Tandon, H.L. (2006). Plant nutrition for food security: A guide for integrated nutrient management. FAO Fertilizer and Plant Nutrition Bulletin 16. Food and Agriculture Organization of the United Nations, Rome, Italy. Pp. 368. DOI: http:// dx.doi.org/10.1017/s0014479706394537

Sahlemedhin Sertus and Taye Bekele. (2000). Procedure for soil and plant analysis. Technical Bulletin No. 74. National Soil Research Center, Ethiopian Agricultural Organization, Addis Ababa, Ethiopia. DOI: http://dx.doi.org/10.21475/ajcs.17.11.05.p373

SeyfuKetema.(1997).Tef [Eragrostis tef( Zucc.) Trotter]. Promoting the conservation and use of underutilized and neglected crops. Biodiversity institute Addis Ababa, Ethiopia. DOI: http:// dx.doi.org/10.1111/j.1439-0523.2010.01782.x

SAS (Statistical Analysis Software). (2002). SAS/STAT User's Guide, Version 9.1.3. SAS institute Inc., Cary, NC. DOI: http://dx.doi.org/10.1177/0894439314544925

Tams, A. R., Mooney, S. J, and Berry, P. M. (2004). The effect of lodging in cereals on morphological properties of the root-soil complex. Super Soil, $3^{\text {rd }}$ Australian New Zealand Soils Conference, 5-9 December, 2004 University of Sydney, Australia. Tri methyl ammonium chloride (CCC).M.Sc. Thesis, University of London, Wye College.pp. 60. DOI: http://dx.doi.org/10.1016/s0065-2113(04)84005-7

Tareke Berehe. (2010) "Report of new and innovative research approaches to increasing productivity of tef. Sasakawa African Association Adis Abeba, Ethiopia. DOI: http://dx.doi. org/10.15406/apar.2015.02.00045

Tareke Berhe and Nigusse Zena, (2008). Results in a trial of system of teff intensification (STI) at Debre zeit, Ethiopia. DOI: http://dx.doi.org/10.1079/pavsnnr201712054 
Tareke Berhe, Zewdie Gebresadik, Sue E.and Hailu Areya.(2013).Boosting tef productivity using improved agronomic practices and appropriate fertilizer. In: Kebebew Assefa,Solomon Chanyalew and Zerihun Tadele(eds.) proceeding of the second international workshop, 7-9 November 2011,Debre Zeit, Ethiopia, pp 133-140. DOI: http://dx.doi. org/10.1002/9781119130765.ch9

Tolosa Shiferaw (2012) Effects of inorganic fertilizer types and sowing methods of variable. DOI: http://dx.doi.org/10.2478/v10045-012-0063-y

Tucker MR (1999) Essential Plant Nutrients: their presence in North Carolina soils and role in plant nutrition. NCDA and SC, USA. (1): 19-31. DOI: http://dx.doi.org/10.1007/978-3-31958841-4_1 